\title{
Anxiety, Depression and Coronary Artery Disease among Patients Undergoing Angiography in Ghaem Hospital, Mashhad, Iran
}

\author{
Mohammad Tajfard1,2, Majid Ghayour-Mobarhan'3, Hamid Reza Rahimi', \\ Mohsen Mouhebati5, Habibollah Esmaeily6, Gordon A. A. Ferns ${ }^{7}$, Latiffah A. Latiff ${ }^{*}$, \\ Farzaneh Tajfiroozeh", Nagmeh Mokhber', Ramin Nazeminezhad4, \\ Homa Falsoleyman ${ }^{5}$, Ali Taghipour ${ }^{6}$, Ahmad Fazli Abdul Aziz ${ }^{9}$, \\ Rosliza A. Manaf' ${ }^{2}$ Zahra Saghiri10, Parichehr Hanachi11
}

${ }^{1}$ Health Sciences Research Center, Department of Health and management, School of Health, Mashhad University of Medical Sciences, Mashhad, Iran

${ }^{2}$ Department of Community Health, Faculty of Medicine and Health Sciences, Universiti Putra Malaysia, Serdang, Selangor, Malaysia

${ }^{3}$ Cardiovascular Research Center, School of Medicine, Mashhad University of Medical Sciences, Mashhad, Iran

${ }^{4}$ Student Research Committee, Department of Modern Sciences \& Technologies, School of Medicine, Mashhad University of Medical Sciences, Mashhad, Iran

${ }^{5}$ Department of Cardiology, School of Medicine, Mashhad University of Medical Sciences, Mashhad, Iran

${ }^{6}$ Health Sciences Research Center, Department of Biostatistics, School of Health, Mashhad University of Medical Sciences, Mashhad, Iran

${ }^{7}$ Brighton \& Sussex Medical School, Falmer, Brighton, UK

${ }^{8}$ Departemet of Psychiatry, School of Medicine, Mashhad University of Medical Sciences, Mashhad, Iran

${ }^{9}$ Department of Medicine, Faculty of Medicine and Health Sciences, University Putra Malaysia, Serdang, Selangor, Malaysia

${ }^{10}$ Department of Biology-Biochemistry, Faculty of Science, Payame Noor University of Mashhad, Mashhad, Iran

${ }^{11}$ Faculty of Science, Biology Department, Biochemistry Unit, Alzahra University, Tehran, Iran

Email: ${ }^{\text {latiffah.latiff@gmail.com }}$

Received 20 March 2014; revised 25 April 2014; accepted 3 May 2014

Copyright (C) 2014 by authors and Scientific Research Publishing Inc.

This work is licensed under the Creative Commons Attribution International License (CC BY).

http://creativecommons.org/licenses/by/4.0/

(c) (i) Open Access

\section{Abstract}

The prevalence of coronary artery disease (CAD) is increasing in Iran. Patients with depression

\footnotetext{
*Corresponding author.
}

How to cite this paper: Tajfard, M., Ghayour-Mobarhan, M., Rahimi, H.R., Mouhebati, M., Esmaeily, H., Ferns, G.A.A., Latiff, L.A., Tajfiroozeh, F., Mokhber, N., Nazeminezhad, R., Falsoleyman, H., Taghipour, A., Aziz, A.F.A., Manaf, R.A., Saghiri, Z. and Hanachi, P. (2014) Anxiety, Depression and Coronary Artery Disease among Patients Undergoing Angiography in Ghaem Hospital, Mashhad, Iran. Health, 6, 1108-1115. http://dx.doi.org/10.4236/health.2014.611137 
who have a myocardial infarction are more likely to die and patients who have depressive symptoms during hospitalization may have increased cardiovascular events. This study aimed to determine the relationship between anxiety, depression and coronary artery disease among patients undergoing angiography in Ghaem Hospital, Mashhad. This was a case-control study conducted between September 2011 and August 2012 among patients undergoing coronary angiography in Ghaem Hospital, Mashhad, Iran. There were 486 cases that were found to have one or more coronary stenoses, with a stenosis of equal or more than $50 \%$ of the diameter of at least one major coronary artery. The other patient group consisted of the patients in whom the coronary artery stenosis was less than $\mathbf{5 0 \%}$ in diameter which was classified as angiography negative, and a control group that consisted of 440 healthy adults aged 18 years old and above who were selected among people who attended for routine medical checkup and medical examination of employment. The dependent variables were Beck Anxiety and Depression Inventory scores and the independent factors were coronary artery disease, and socioeconomic profiles. Validated and reliability-tested questionnaires were used for data collection. The mean age of patients was $55.75 \pm 10.64$ years and in the healthy group was $55.83 \pm 8.55$ years; there was no significant difference in age between subject groups $(p=0.897)$ nor a significant difference in the gender frequency distribution of subjects $(p=0.610)$. There was a significant difference in anxiety score between the Angio positive and Angio negative patients and healthy control subjects $(p<0.001)$. There was a statistical significant difference between groups for the anxiety score $(p<0.001)$. However, the subjects did not differ significantly for BDI depression score $(p=0.534)$. A significant positive relationship was found between anxiety score and depression score when data were analyzed by Pearson's test ( $p<$ 0.001, Pearson's correlation $=0.582$ ). Depression and anxiety are associated among patients with CAD undergoing coronary angiography sessions.

\section{Keywords}

Coronary Artery Disease, Anxiety, Depression, Angiography

\section{Introduction}

Coronary artery disease (CAD) is a major problem globally and it is more hazardous for men than for women. The statistic mortality shows that $34 \%$ men and $28 \%$ women die because of this problem. CAD has a number of risk determinants, such as lifestyle, psychological factors, environment [1] [2], age, emotional status, and smoking [3]. CAD is the end-point of a chronic and progressive condition that leads to heart failure and death [4] [5].

Depression and anxiety are also common disorders within all populations [3], but few studies have paid attention to the influences of depression and anxiety on physical health [6]. Anxiety sensitivity (AS) is different for each person since the symptoms concerning fear are associated with anxiety arousal, and anxiety has negative somatic signs and to a larger extent affects those who are psychologically vulnerable, such as those with depression and depressive symptoms [7]. Studies show that women have a higher prevalence of these symptoms than men [3].

We know that there is an association between depression and physical health and it is thought to be an important risk factor for heart diseases [8], and mood state has been identified as a determinant of quality of life in those who have coronary disease [9]. One out of every five patients with coronary patients has depression symptoms [6] [10] [11]. CAD reduces the life quality of the patient, for example, performance of life activities, ability to use medication and diet therapies [10]. The degree of depression and anxiety is associated with a greater decline in physical functioning of patient with heart failure [6]. Depression and anxiety appear to be highly overlapping with each other and they cause an increased risk more than $80 \%$ of CVD following when adjusted for CAD risk factors [12], but we should know that depression and coronary heart diseases are reversible, and coronary heart diseases may lead to depression [13].

Recently studies have shown that patients with depression who have myocardial infarction are more likely to die and the patients who have depressive symptom during hospitalization probably have increased cardiovascu- 
lar events [8] [14]. Mood state may lead to hospitalization even after correction for demographic and medical factors [6]. Many studies have reported that mood disorders have an important impact on the outcome of cardiac transplantation; depressed patients with heart transplant have a tendency to be less active than those without [15] [16]. Social support is an important factor of psychology and it is useful for influence on heart, for example, patients with heart failure who are unmarried or seldom visit their family or friends have a significantly higher risk of serious impairment in activities [6]. To our knowledge, there are a few data to look at the association between mood status and CAD; therefore, we hope to investigate the association between anxiety and depression in CAD potions based on angiography.

\section{Methods \& Materials}

\subsection{Participants and Procedure}

Coronary angiograms were undertaken using routine procedures and were performed by a specialist cardiologist. These patients who undergoing coronary angiography, especially for stable angina, and at least as more as one object test of myocardial ischemia such as Dobutamin stress or exercise stress test [17]. 486 patients (247 males and 239 females) were recruited for this study. Patients were selected from adult ( $>18$ years of age). All subjects were without a past clinical history of angiography and heart surgery. The subjects consisted of three groups, patients group and healthy group (control group). The patients were classified into two groups. The first group consisted of the patients whose result of angiography shows one or more stenosis with the occlusion of $>50 \%$ of the diameter of at least one major coronary artery and so they would be considered as a significant angiography positive (case group). And the second group consists of the patients in whom the coronary artery stenosis was $<50 \%$ in diameter which is classified as not having significant (angiography negative) [18]-[20]. 440 healthy (231 males and 209 females) from adult (beyond the age of 18) who were selected among people who come for routine medical checkup and employment Medical examination at employment.

All subject full the questionnaires about physical and mental health functioning, smoking, depression, and anxiety test. This study focused on overlapping CAD, depression, and anxiety.

\subsection{Anthropometric and Other Measurements}

Anthropometric measurements for each subject including height, weight, by using standard protocols were done. The calculation of body mass index (BMI) was performed as weight $(\mathrm{Kg})$ divided by height squared $\left(\mathrm{m}^{2}\right)$ [21].

\subsection{Assessment of Depression and Anxiety}

The Beck Anxiety Inventory (BAI) is a 21-questionstion multiple-choice self-report inventory that is used for measuring the severity of an individual's anxiety [22]. It assesses two factors: somatic, that applied 12 items explaining physiological symptoms, such as, "numbness or tingling", "feeling dizzy or lightheaded" and subjective anxiety and panic, that applied the remaining 9 items of the BAI measures, such as "fear of the worst happening" and "unable to relax" [22]. According to the Anxiety beck questioner score, if a person get 7 or less from this test has minimal anxiety, mild anxiety score is 8 - 15 and moderate anxiety is 16 - 25 and more than 25 is severe anxiety [23] [24]. The Beck Depression Inventory (BDI) is 21-item; self-report rating inventory the measurement of characteristic attitudes and symptoms of depression was done by the Beck. Beck developed a triad of negative cognitions about the world, the future and the self which play a major role in depression. If a person get 15 or less from this test has no depression, mild depression is $16-30$, moderate depression, score is 31 - 46 and severe depression, is more than 47 [24]. These questioners were given to subjects before any procedures.

\subsection{Statistical Analysis}

Statistical analysis were used the Statistical Package for Social Sciences version 16. Descriptive statistics (frequency, mean, standard deviation) determined for all variables. Differences in coronary artery stenos is (Angioor Angio+) were analyzed by the chi-square test for categorical variables. We used categorical depression and anxiety base on score of them. Multivariate analyses were used to examine effects of demographic variable (such as weight, Height, BMI) on coronary artery disease. 


\section{Results}

Nine hundred and twenty six subjects were evaluated for depression and anxiety. Four hundred and eighty six persons had a history of cardiac signs or symptoms and 440 persons were healthy subjects. The mean age of all subjects were $55.79 \pm 9.65$ years old and there was no significant difference between patients and healthy subjects $(\mathrm{p}=0.897)$ also no statistical significant difference were found in gender of subjects between groups $(\mathrm{p}=$ 0.610) (Table 1).

When subjects were divided into patient and healthy subjects there was a statistical significant difference between groups in anxiety score $(\mathrm{p}<0.001)$. But the subjects had no significant difference in depression score assessed by the BDI $(\mathrm{p}=0.534)$ (Table 1$)$.

A significant statistical effect of gender on depression scores was found for healthy and patient groups $(\mathrm{p}<$ 0.001) (Table 2).

As shown in Table 3, there was a significant difference between angiography positive, negative and healthy subjects in anxiety score and also in the number of persons who had minimal anxiety $(\mathrm{p}<0.001)$. Other category of anxiety score (mild, moderate and severe) had no difference among three groups ( $p>0.05$ ) (Table 3 ).

According to that the angiography results subjects can be divided according to the number of involved coronary vessels. Depression and anxiety scores results in Table 4 based on the number of vessels involved are shown. Again, there were significant differences in anxiety among groups. After post HOC test were performed significant difference was found between healthy and angiography negative group $(\mathrm{p}<0.001)$.

In this study a significant direct linear correlation was found between anxiety score and depression score when data were analyzed by Pearson test $(p<0.001$, Pearson correlation $=0.582)$ (Figure 1$)$. This correlation either found in healthy and patients group.

\section{Discussion}

Depression is one of the main risk factors, which leads to morbidity and mortality resulted from coronary artery disease (CAD). Depressed persons with initially good medical health have an elevated incidence of CHD. In addition, the risk of mortality is increased in people who are depressed after myocardial infarction (MI). Another important point is that depression is also associated with elevated expression of inflammatory biomarkers [25].

According to a recent meta-analysis, perceived stress is associated with the risk of coronary artery disease [26]. Individuals with anxiety disorders or depressed mood are prone to unhealthier lifestyle [27]. This lifestyle might lead to increased cardiovascular risk factors, associated with for example inactivity, smoking, unhealthy nutrition [27].

Table 1. Age, sex, depression score, and anxiety score when subjects were divided to patients and healthy group.

\begin{tabular}{|c|c|c|c|c|}
\hline & & $\begin{array}{l}\text { Patients } \\
\mathrm{n}=486\end{array}$ & $\begin{array}{l}\text { Healthy } \\
n=440\end{array}$ & $\mathrm{p}$ Value \\
\hline & Age (year) & $55.75 \pm 10.64$ & $55.83 \pm 8.55$ & 0.897 \\
\hline \multirow{2}{*}{ Sex } & Male & $247(50.8)$ & $231(52.5)$ & \multirow{2}{*}{0.610} \\
\hline & Female & $239(49.2)$ & 209 (47.5) & \\
\hline & Anxiety score & $10.62 \pm 9.82$ & $8.38 \pm 8.62$ & $<0.001$ \\
\hline & Depression score & $10.37 \pm 8.20$ & $10.70 \pm 8.38$ & 0.534 \\
\hline
\end{tabular}

Data shown as: Mean \pm SD or N (\%).

Table 2. Distribution of gender in depression in patients and healthy controls.

\begin{tabular}{|c|c|c|c|c|c|}
\hline \multirow[b]{2}{*}{ Depression } & \multicolumn{2}{|c|}{$\begin{array}{l}\text { Patients } \\
\mathrm{n}=486\end{array}$} & \multicolumn{2}{|c|}{$\begin{array}{l}\text { Healthy } \\
n=440\end{array}$} & \multirow{2}{*}{ p Value } \\
\hline & Male & Female & Male & Female & \\
\hline No depression & $215(87.0)$ & $160(70)$ & $188(81.5)$ & 137 (65.5) & \multirow{2}{*}{$\begin{array}{l}\mathrm{p}_{1}<0.001 \\
\mathrm{p}_{2}<0.001 \\
\mathrm{p}_{3}<0.001\end{array}$} \\
\hline Depressed subject & $32(13.0)$ & 79 (30) & 43 (18.5) & $72(34.5)$ & \\
\hline
\end{tabular}

$\mathrm{p}_{1}$ : Compared two groups of healthy, patients for depression and gender overall. $\mathrm{p}_{2}$ : Compared in patients group for gender depression. $\mathrm{p}_{3}$ : Compared in healthy group for gender and depression. Data shown as: N (\%). 
Table 3. Depression score and anxiety score also their category when subjects were divided to angiography positive, negative and healthy group.

\begin{tabular}{|c|c|c|c|c|c|}
\hline & & \multicolumn{2}{|c|}{ Patient } & \multirow{2}{*}{$\begin{array}{l}\text { Healthy } \\
(\mathrm{N}=440)\end{array}$} & \multirow[b]{2}{*}{ p Value } \\
\hline & & $\begin{array}{c}\text { Angio- } \\
(\mathrm{N}=201)\end{array}$ & $\begin{array}{c}\text { Angio }+ \\
(\mathrm{N}=285)\end{array}$ & & \\
\hline \multirow{5}{*}{$\begin{array}{c}\text { Depression } \\
\text { category }\end{array}$} & Depression score & $11.27 \pm 8.85$ & $9.73 \pm 7.66$ & $10.70 \pm 8.38$ & 0.108 \\
\hline & No depression & $145(72.0)$ & $230(80.7)$ & $325(74.0)$ & 0.049 \\
\hline & Mild depression & $52(26.0)$ & $50(17.5)$ & $106(24.0)$ & 0.051 \\
\hline & Moderate depression & $4(2.0)$ & $5(2.0)$ & $9(2.0)$ & 0.961 \\
\hline & Anxiety score & $11.53 \pm 10.03$ & $9.98 \pm 9.63$ & $8.38 \pm 8.62$ & $<0.001$ \\
\hline \multirow{4}{*}{$\begin{array}{l}\text { Anxiety } \\
\text { category }\end{array}$} & Minimal anxiety & $86(42.8)$ & $143(50.2)$ & $261(59.3)$ & $<0.001$ \\
\hline & Mild anxiety & $62(30.8)$ & $78(27.4)$ & $108(24.5)$ & 0.239 \\
\hline & Moderate anxiety & 34 (16.9) & 39 (13.7) & $46(10.5)$ & 0.067 \\
\hline & Severe anxiety & $19(9.5)$ & $25(8.8)$ & $25(5.7)$ & 0.143 \\
\hline
\end{tabular}

Data shown as: Mean \pm SD or N (\%).

Table 4. Depression score and anxiety score when subjects were divided to angiography positive (single vessel disease, two vessel disease, three vessel disease), negative and healthy group.

\begin{tabular}{ccccccc}
\hline & \multicolumn{3}{c}{ Patient } & & & \\
& \multicolumn{1}{c}{$\begin{array}{c}\text { Angio- } \\
(\mathrm{n}=201)\end{array}$} & $\begin{array}{c}\text { SVD } \\
(\mathrm{n}=88)\end{array}$ & $\begin{array}{c}\text { 2VD } \\
(\mathrm{n}=58)\end{array}$ & $\begin{array}{c}\text { 3VD } \\
(\mathrm{n}=139)\end{array}$ & $\begin{array}{c}\mathrm{p} \text { Value } \\
(\mathrm{n}=440)\end{array}$ \\
\hline Depression score & $11.27 \pm 8.85$ & $10.10 \pm 7.58$ & $10.71 \pm 7.88$ & $9.09 \pm 7.60$ & $10.70 \pm 8.38$ \\
Anxiety score & $11.53 \pm 10.03$ & $10.69 \pm 9.76$ & $11.03 \pm 10.55$ & $9.09 \pm 9.12$ & $8.38 \pm 8.62$ & $<0.181$ \\
\hline
\end{tabular}

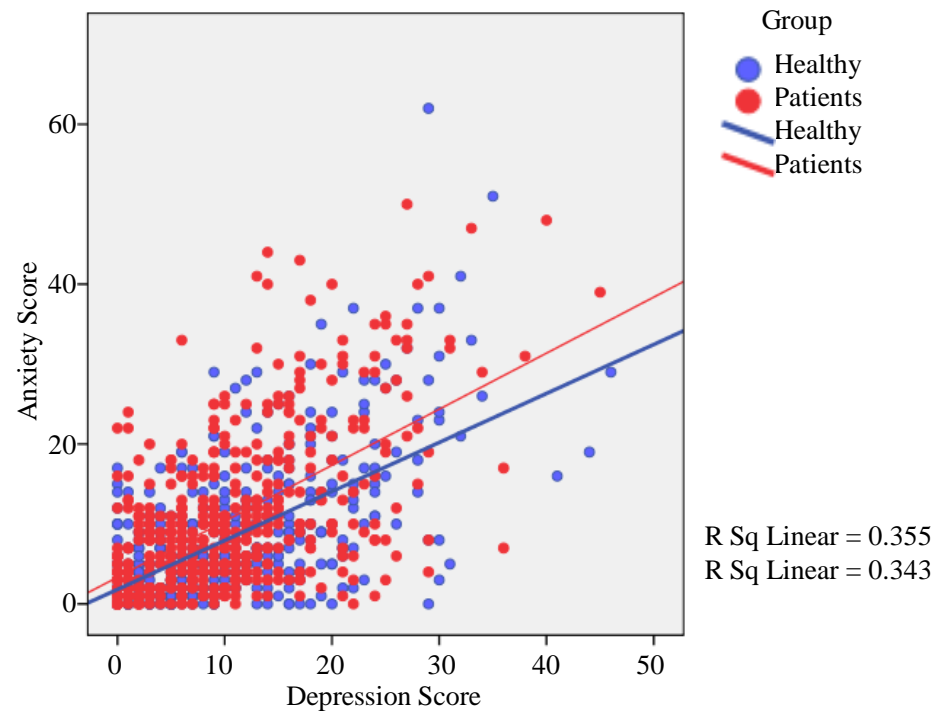

Figure 1. Correlation between anxiety and depression score in healthy and patient group.

In this study 926 healthy and suspected to cardiovascular disease subjects were tested for depression and anxiety by Beck questionnaire. The results of these tests showed that the anxiety is associated with CAD and the angiography positive or negative persons (subjects who had cardiovascular sign and symptoms) had high incidence of anxiety so that the anxiety score and subjects that have minimal anxiety are significant difference between groups ( $<$ 0.05). Same findings were reported in some other studies [25] [28] [29].

In Lindeberg's study “exhaustion predicted CHD in both men and women, but its independence from depres- 
sion and anxiety was demonstrated only in men” [3] an according to Table 2, significant difference found between healthy and patients subjects in gender and depression.

Although there is no significant difference between depression score in healthy and patients group but there is statistical significant difference were observed between depression and no depression categories (no $<15$ and yes $>15$ ) among groups $(\mathrm{p}<0.05)$ (Table 3 ) and also there were a good linear correlation found between anxiety and depression score (Figure 1) this correlation are found in both healthy and patient group.

Patients who suffered from severe depression probably have no adequate emotional activity for participate to any researches so it is one of our limitations. Process of in Table 2 shows that emotional desire in research participation is loss.

\section{Conclusion}

In conclusion, depression and anxiety Beck scores have great correlation in healthy and CAD patients. We found a good association between anxiety and angiography positive, angiography negative and healthy subjects. So psychiatry visits by specialties in cardiovascular patients are recommended for case fining in depression mood and anxiety disorder.

\section{Acknowledgements}

The Mashhad University of Medical Science Research Council supported this research. This paper is the subject thesis of Mr. Mohammad Tajfard, which is the PhD Candidate of the community health in University Putra Malaysia. Authors would like to thank Center for International Scientific Studies and Collaboration for their support.

\section{Ethical Issue}

The study was conducted in accordance with the principles of Declaration of Helsinki 1996 version and Good Clinical Practice standards. The study protocol, informed-consent form, and the other study related documents were reviewed and approved by Human Research Ethics Committee of Mashhad University of Medical Sciences (Ethics registration number: MUMS/900671) also Medical Research Ethics Committee of Faculty of Medicine and Health Sciences, Universiti Putra Malaysia (Ethics Committee 15 September 2011).

\section{Conflict of Interest Statement}

The authors indicate no potential conflicts of interest.

\section{References}

[1] Antonogeorgos, G., Panagiotakos, D.B., Pitsavos, C., Papageorgiou, C., Chrysohoou, C., Papadimitriou, G.N., et al. (2012) Understanding the Role of Depression and Anxiety on Cardiovascular Disease Risk, Using Structural Equation Modeling; the Mediating Effect of the Mediterranean Diet and Physical Activity: The ATTICA Study. Annals of Epidemiology, 22, 630-637. http://dx.doi.org/10.1016/j.annepidem.2012.06.103

[2] Murray, C. and Lopez, A. (1996) Summary: The Global Burden of Disease: A Comprehensive Assessment of Mortality and Disability from Diseases, Injuries, and Risk Factors in 1990 and Projected to 2020. Harvard University Press, Cambridge.

[3] Lindeberg, S.I., Rosvall, M. and Ostergren, P.O. (2012) Exhaustion Predicts Coronary Heart Disease Independently of Symptoms of Depression and Anxiety in Men But Not in Women. Journal of Psychosomatic Research, 72, 17-21. http://dx.doi.org/10.1016/j.jpsychores.2011.09.001

[4] Damen, N.L., Pelle, A.J., Szabo, B.M. and Pedersen, S.S. (2012) Symptoms of Anxiety and Cardiac Hospitalizations at 12 Months in Patients with Heart Failure. Journal of General Internal Medicine, 27, 345-350. http://dx.doi.org/10.1007/s11606-011-1843-1

[5] Lloyd-Jones, D., Adams, R., Carnethon, M., De Simone, G., Ferguson, T.B., Flegal, K., et al. (2009) Heart Disease and Stroke Statistics - 2009 Update: A Report from the American Heart Association Statistics Committee and Stroke Statistics Subcommittee. Circulation, 119, 480-486. http://dx.doi.org/10.1161/CIRCULATIONAHA.108.191259

[6] Shen, B.J., Eisenberg, S.A., Maeda, U., Farrell, K.A., Schwarz, E.R., Penedo, F.J., et al. (2011) Depression and Anxiety Predict Decline in Physical Health Functioning in Patients with Heart Failure. Annals of Behavioral Medicine, 41, 373-382. http://dx.doi.org/10.1007/s12160-010-9251-z 
[7] Tull, M.T. and Gratz, K.L. (2008) Further Examination of the Relationship between Anxiety Sensitivity and Depression: The Mediating Role of Experiential Avoidance and Difficulties Engaging in Goal-Directed Behavior When Distressed. Journal of Anxiety Disorders, 22, 199-210. http://dx.doi.org/10.1016/j.janxdis.2007.03.005

[8] Blumenfield, M., Suojanen, J.K. and Weiss, C. (2012) Public Awareness about the Connection between Depression and Physical Health: Specifically Heart Disease. Psychiatric Quarterly, 83, 259-269. http://dx.doi.org/10.1007/s11126-011-9199-6

[9] Pedersen, S.S., Herrmann-Lingen, C., de Jonge, P. and Scherer, M. (2010) Type D Personality Is a Predictor of Poor Emotional Quality of Life in Primary Care Heart Failure Patients Independent of Depressive Symptoms and New York Heart Association Functional Class. Journal of Behavioral Medicine, 33, 72-80. http://dx.doi.org/10.1007/s10865-009-9236-1

[10] Steinberg, G., Lossnitzer, N., Schellberg, D., Mueller-Tasch, T., Krueger, C., Haass, M., et al. (2011) Peak Oxygen Uptake and Left Ventricular Ejection Fraction, But Not Depressive Symptoms, Are Associated with Cognitive Impairment in Patients with Chronic Heart Failure. International Journal of General Medicine, 4, 879-887.

[11] Rutledge, T., Reis, V.A., Linke, S.E., Greenberg, B.H. and Mills, P.J. (2006) Depression in Heart Failure a MetaAnalytic Review of Prevalence, Intervention Effects, and Associations with Clinical Outcomes. Journal of the American College of Cardiology, 48, 1527-1537. http://dx.doi.org/10.1016/j.jacc.2006.06.055

[12] Gallagher, D., O’Regan, C., Savva, G.M., Cronin, H., Lawlor, B.A. and Kenny, R.A. (2012) Depression, Anxiety and Cardiovascular Disease: Which Symptoms Are Associated with Increased Risk in Community Dwelling Older Adults? Journal of Affective Disorders, 142, 132-138. http://dx.doi.org/10.1016/j.jad.2012.04.012

[13] Gilani, K.A., Fallahi, B., Jamak, M.E. and Mahani, M.S. (2006) Effects of Depression on Myocardial Perfusion Scintigraphy [Persian]. Iranian Journal of Nuclear Medicine, 4, 1-7.

[14] Burg, M.M. and Abrams, D. (2001) Depression in Chronic Medical Illness: The Case of Coronary Heart Disease. Journal of Clinical Psychology, 57, 1323-1337. http://dx.doi.org/10.1002/jclp.1100

[15] Madan, A., White-Williams, C., Borckardt, J.J., Burker, E.J., Milsom, V.A., Pelic, C.M., et al. (2012) Beyond Rose Colored Glasses: The Adaptive Role of Depressive and Anxious Symptoms among Individuals with Heart Failure Who Were Evaluated for Transplantation. Clinical Transplantation, 26, E223-E231. http://dx.doi.org/10.1111/j.1399-0012.2012.01613.x

[16] Spaderna, H., Zahn, D., Schleithoff, S.S., Stadlbauer, T., Rupprecht, L., Smits, J.M., et al. (2010) Depression and Disease Severity as Correlates of Everyday Physical Activity in Heart Transplant Candidates. Transplant International, 23, 813-822. http://dx.doi.org/10.1111/j.1432-2277.2010.01056.x

[17] Alamdari, D.H., Ghayour-Mobarhan, M., Tavallaie, S., Parizadeh, M.R., Moohebati, M., Ghafoori, F., et al. (2008) Prooxidant-Antioxidant Balance as a New Risk Factor in Patients with Angiographically Defined Coronary Artery Disease. Clinical Biochemistry, 41, 375-380. http://dx.doi.org/10.1016/j.clinbiochem.2007.12.008

[18] Kazemi-Bajestani, S.M., Ghayour-Mobarhan, M., Ebrahimi, M., Moohebati, M., Esmaeili, H.A. and Ferns, G.A. (2007) C-Reactive Protein Associated with Coronary Artery Disease in Iranian Patients with Angiographically Defined Coronary Artery Disease. Clinical Laboratory, 53, 49-56.

[19] Geluk, C.A., Post, W.J., Hillege, H.L., Tio, R.A., Tijssen, J.G., van Dijk, R.B., et al. (2008) C-Reactive Protein and Angiographic Characteristics of Stable and Unstable Coronary Artery Disease: Data from the Prospective PREVEND Cohort. Atherosclerosis, 196, 372-382. http://dx.doi.org/10.1016/j.atherosclerosis.2006.11.013

[20] Nezhad, M., Ghanbari, P., Shahryari, B. and Aghasadeghi, K. (2009) C-Reactive Protein in Angiographically Documented Stable Coronary Disease. Iranian Cardiovascular Research Journal, 3, 97-101.

[21] Kazemi-Bajestani, S.M., Ghayour-Mobarhan, M., Ebrahimi, M., Moohebati, M., Esmaeili, H.A., Parizadeh, M.R., et al. (2007) Serum Copper and Zinc Concentrations Are Lower in Iranian Patients with Angiographically Defined Coronary Artery Disease Than in Subjects with a Normal Angiogram. Journal of Trace Elements in Medicine and Biology, 21, 22-28. http://dx.doi.org/10.1016/j.jtemb.2006.11.005

[22] Leyfer, O.T., Ruberg, J.L. and Woodruff-Borden, J. (2206) Examination of the Utility of the Beck Anxiety Inventory and Its Factors as a Screener for Anxiety Disorders. Journal of Anxiety Disorders, 20, 444-458. http://dx.doi.org/10.1016/j.janxdis.2005.05.004

[23] Beck, A.T., Steer, R.A. and Carbin, M.G. (1998) Psychometric Properties of the Beck Depression Inventory: TwentyFive Years of Evaluation. Clinical Psychology Review, 8, 77-100. http://dx.doi.org/10.1016/0272-7358(88)90050-5

[24] Beck, A.T., Ward, C.H., Mendelson, M., Mock, J. and Erbaugh, J. (1961) An Inventory for Measuring Depression. Archives of General Psychiatry, 4, 561-571. http://dx.doi.org/10.1001/archpsyc.1961.01710120031004

[25] Miller, G.E., Freedland, K.E., Carney, R.M., Stetler, C.A. and Banks, W.A. (2003) Pathways Linking Depression, Adiposity, and Inflammatory Markers in Healthy Young Adults. Brain, Behavior, and Immunity, 17, 276-285. http://dx.doi.org/10.1016/S0889-1591(03)00057-6 
[26] Richardson, S., Shaffer, J.A., Falzon, L., Krupka, D., Davidson, K.W. and Edmondson, D. (2012) Meta-Analysis of Perceived Stress and Its Association with Incident Coronary Heart Disease. American Journal of Cardiology, 110, 1711-1716. http://dx.doi.org/10.1016/j.amjcard.2012.08.004

[27] Rozanski, A., Blumenthal, J.A. and Kaplan, J. (1999) Impact of Psychological Factors on the Pathogenesis of Cardiovascular Disease and Implications for Therapy. Circulation, 99, 2192-2217. http://dx.doi.org/10.1161/01.CIR.99.16.2192

[28] Kawachi, I., Sparrow, D., Vokonas, P.S. and Weiss, S.T. (1994) Symptoms of Anxiety and Risk of Coronary Heart Disease. The Normative Aging Study. Circulation, 90, 2225-2229. http://dx.doi.org/10.1161/01.CIR.90.5.2225

[29] Kawachi, I., Colditz, G.A., Ascherio, A., Rimm, E.B., Giovannucci, E., Stampfer, M.J., et al. (1994) Prospective Study of Phobic Anxiety and Risk of Coronary Heart Disease in Men. Circulation, 89, 1992-1997. http://dx.doi.org/10.1161/01.CIR.89.5.1992 